\title{
Theoretical Study of the Process of Separating the Tobacco Leaf from the Stem
}

\author{
Sergey Papusha, ${ }^{1, *}$, and Andrey Domrin ${ }^{1}$ \\ ${ }^{1}$ Kuban State Agrarian University named after I.T. Trubilin, Krasnodar, Russia
}

\begin{abstract}
The article is devoted to the cleaning of tobacco leaves by the leaf-by-leaf method, using a roller-type separating device acting on the object of cleaning with a drum knife having cutting edges, forming leafseparating cells in the working area. The subject of these studies is highly specialized and relates to the field of agricultural engineering. Tobacco plants were selected as the object of processing. The purpose of the research was the theoretical substantiation of the interaction of tobacco stalks with the leaf-separating apparatus in the harvesting process. The article is of a research type, which is expressed in the fact that a theoretical analysis of the interaction of a tobacco plant with a leaf-separating device of a knife-drum type in the cleaning process is carried out. As a result of the research, dependencies were obtained that allow determining the design and technological parameters of the separating apparatus for separating a tobacco leaf. The conclusions present the main results achieved so far.
\end{abstract}

Agricultural production of tobacco raw materials together with enterprises for their industrial processing is designed to meet the need of population for high-quality and lowtoxic smoking products [3]. It is necessary to increase the profitability of tobacco production, which is possible only with the use of machine technologies, in order to further improve the efficiency of the tobacco industry [2].

The tobacco plant is characterized by a consistent, tiered maturation of leaves on the stem, so they are removed in several steps (breaking).

The use of a working body on a harvesting machine that works with the use of actively rotating drums with cutting edges mounted on chain contours, as well as additionally equipped with a pneumatic system and retaining rollers, will increase the completeness of leaf separation by changing the cutting process, reduce injury to the leaf blade due to faster the removal of leaves from the separation zone $[1,4]$.

According to the design and technological scheme [1,5], the tobacco leaf is separated from the stem by cutting drums.

The diagram of the interaction of the air flow and the tobacco leaf is shown in Figure 1.

Since when the height of the cut changes, the value of the leaf's length changes, let us assume that the change in the average value occurs proportionally, then to keep the contact area in the zone of the center of gravity, it is necessary that the length of the semi-axis is equal to:

\footnotetext{
*Corresponding author: serega0318@mail.ru
} 

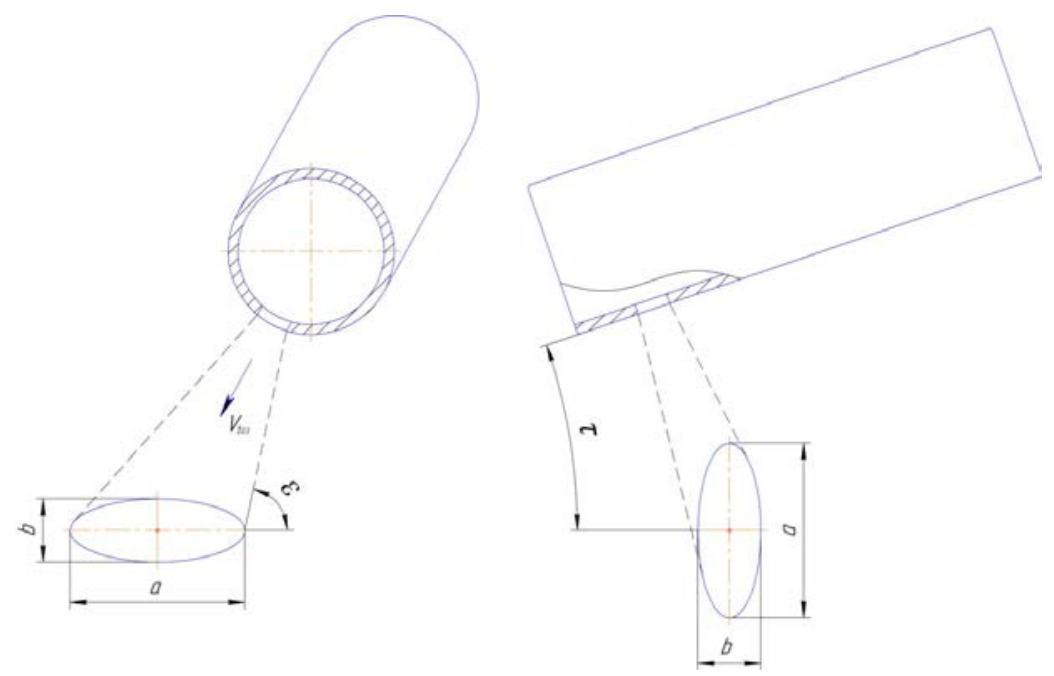

Fig. 1. Diagram of the interaction of the air flow and the tobacco leaf

$$
a=2\left(3 S_{R_{H}}+3 S_{\text {чер }}+3 S_{l_{\text {лист }}}\right) \cos (90-\varepsilon),
$$

where from:

$$
\varepsilon=\arcsin \frac{a}{2\left(3 S_{R_{H}}+3 S_{\text {чер }}+3 S_{l_{\text {mum }}}\right)} .
$$

Thus, the angle of the air supply installation $\varepsilon$ in the transverse plane should vary depending on the height of the cut.

Since the cutting force decreases with a change in the height of the cut, it is necessary to ensure a change in the longitudinal angle of the air duct installation, which will ensure the orientation of the sheet and increase the completeness of the gathering with less damage to the leaf.

The force of the air flow pressure will be the following:

$$
F_{p}=c S_{\mu} \rho \frac{V_{a}^{2}}{2},
$$

where $F_{p}$ - air flow pressure force, $H$;

$c$ - coefficient of resistance of the medium;

$\rho$ - air density, $\mathrm{kg} / \mathrm{m}^{3}$;

$S_{M}-$ midsection, $\mathrm{m}^{2}$;

$V_{a}$ - speed of the air flow, $\mathrm{m} / \mathrm{s}$.

Since it is necessary to balance the forces in order to hold the leaf during cutting, then transforming the expression (2) we get:

$$
S_{M}=\frac{2 R_{b}}{c \rho V_{a}^{2}}
$$

Taking into account the expression (1), the length of the semi-axis of the ellipse will be: 


$$
b=2\left(3 S_{R_{H}}+3 S_{M}+3 S_{l_{\text {leaf }}}\right) \cos \tau
$$

where $\tau$ - angle of the air supply installation in the longitudinal plane, deg.

Equating the contact area of the air flow $S_{\text {contact }}$ and the midsection $S_{m}$ of expressions (1 and 3) and taking into account expression (4), we obtain:

$$
\frac{2 R_{b}}{c \rho V_{a}^{2}}=\pi a 2\left(3 S_{R_{H}}+3 S_{m}+3 S_{\text {leaf }}\right) \cos \tau,
$$

After the conversion:

$$
\tau=\arccos \frac{R_{b}}{c \rho V_{a}^{2} \pi a\left(3 S_{R_{H}}+3 S_{m}+3 S_{l \text { leaf }}\right)} .
$$

Expression (5) shows the dependence of the change in the angle of the air supply installation in the longitudinal plane on the change in the regime and biometric parameters.

As a result of the conducted research, it can be concluded that:

1. The article presents a design and technological scheme of the apparatus for harvesting tobacco of the middle and upper breaks, which allows to increase the technological efficiency and reliability of the process;

2. Expressions characterizing the trajectory and absolute velocity of an arbitrary point of the cutting edge of the drum are obtained;

3. The analysis of obtained dependencies allows us to conclude that when the leaf is cut, it will remain in the leaf separation zone, which will increase the completeness of harvesting.

\section{References}

1. S.K. Papusha, S.V. Belousov, A.E. Bogus. V.I. Konovalov, International Journal of Applied Engineering Research (IJAER), Theoretical studies of the tobacco stalk interaction with the leaf-separating unit, Volume 11, Number 8 (2016)

2. S.K. Papusha, A.E. Bogus, V.I. Konovalov, MATEC Web of Conferences. 2018 International Conference on Modern Trends in Manufacturing Technologies and Equipment ICMTMTE 2018, Interaction of rotary working body of roller type with the object of processing, C. 05007, (2018).

3. S.K. Papusha, E.I. Vinevsky, V.I. Konovalov, S.I. Konovalov, O.A. Sterligov, Multidisciplinary Network Electronic Scientific Journal of the Kuban State Agrarian University, Theoretical research of the tobacco leaf separation from the stalk, № 126. p. 289-303, (2017).

4. Patent 2311013 Russian Federation, MPK A01D 45/16. Apparatus for separating tobacco leaves [Text]/ E. I. Vinevsky, N. N. Vinevskaya, E. V. Shidlovsky, I. B. Poyarkov, A. E. Petriy, I. I. Dyachkin, S. K. Papusha; applicant and patent holder of FSBSI All-Russian Research Institute of Tobacco, Makhorka and Tobacco Products. - № 2006106854/12; claimed 06.03.2006; published 27.11.2007, Bul. № 28. - 7 p.: illustrated.

5. E. I. Vinevsky, A. E. Lysenko, I. I. Dyachkin, N. N. Vinevskaya, G. V. Popov, A. I. Petriy, K. G. Gromov, E. V. Shidlovsky, A. V. Ognyanik, Achievements of science and technology of AIC, New machinery for tobacco growing [Text], № 6, p. 42-45, (2007). 